\title{
Evaluating the Impact of Expansion on Urban Thermal Surroundings: A Case Study of Lahore Metropolitan city, Pakistan
}

\author{
Usman Ahmed Khan* \\ Department of Space Technology Application, Beihang University, Beijing, China
}

Received: 2 March 2020

Accepted: 21 November 2020

Published online: 31 December 2020

\begin{abstract}
Urbanization directly affects the existing infrastructure, landscape modification, environmental contamination and traffic pollution especially if there is lack of urban planning. Recently, the rapid urban sprawl has resulted in less developed green areas and has devastating environmental consequences. This study was aimed to study the past urban expansion rates and Measure LST from satellite data. The Land use land cover (LULC) maps of years 1996, 2010, 2013, and 2017 were generated using Landsat satellite images. Four main classes i.e. water, urban, bare land and vegetation were identified using unsupervised classification with iterative self-organizing data analysis (isodata) technique. The LST from satellite thermal data can be derived from different procedures:atmospheric, radiometric calibrations and surface emissivity corrections, classification of spatial changeability in land-cover. Different methods and formulas were used in the algorithm that successfully retrieves the land surface temperature to help us study the thermal environment of the ground surface. To verify the algorithm, the land surface temperature and the near-air temperature were compared. The results showed that, From 1996-2017 urban areas increased to about considerable increase of about $48 \%$.few areas of city also shown in reduction in LST from year 1996-2017that actually began their transitional phase from rural to urban LULC.Mean temperature of city increased averagely about $1^{\circ} \mathrm{C}$ each year in the month of October. The green and vegetative areas witnessed a decrease in area while higher number of pixels increased in urban class.
\end{abstract}

Keywords: Landscape Changes, LULC, urban sprawl, LST

\section{Introduction}

Due to rapid rates of urbanization across the globe, biophysical, environmental elements are at high risk. With everyday passing the subject of urban heat and LST have wide interest in remote sensing and GIS (Guo et al. 2012). Muhammadi et al. (2012) delimited urban growth as the extent of urbanization which mainly due to migration and population growth, and has an adverse effect on the physical environmental elements and natural resource. Nowadays urban planner and policy makers have categories settled areas into rural and urban. Due to greater markets access from rural areas and business

\footnotetext{
* Corresponding author: Usman Ahmed Khan
} e-mail: hafiz_usmankhan@hotmail.com 
hubs along with political power, transportation, better health, education, and communication facilities people use to live near cities urban areas. With the passage of time as cities growing rapidly problems are growing as well, stress on natural resources and surrounding areas increase but also increased the amount stressin planning and management that was prerequisite to keep those cities on the trot.

For physical environmentalists and policy makers urbanization is an important topic (Jat et al. 2008).due to urbanization dramatic changes occurs in LULC around urban expansion areas. Usually green areas including forest and agriculture leads to subsequent transformation to build up areas (Rimal 2012). By the growth of urbanization man made features increases as trade of decrease in natural land covers like vegetation, water bodies and environment. Urban expansion actually alters the land surface characteristics which include soil moisture, surface albedo and land surface temperature.noteable temperature difference occurs between rural and urban areas around urbanization, construction material like asphalt and other roads pavements absorb energy at day time and emit at night time in urban areas, which is quite difference in suburban and rural areas which most of part is covered with vegetation which is less absorbent to heat at day time(Gallo et al. 1993; Matthews 2012).According to Vernberg et al. (1996) urbanization has adverse effects on health and human activities. Pollution is another major problem caused by urbanizatioon. Pollutants sustain in environment in different form i.e. it can be liquid, solid, gas and even in form of energy. Waste of energy due to daily human activities cause unwanted effects, like in access of heat in environment. When urbanization occursit effects existing environment setup and energy balance in environment by modifying the transfer and storage of energy.

This gives upswing to the singularity called the Urban Heat Island (UHI). "The surface urban heat island (SUHI) effect can be defined as the increased in urban areas temperature in contrast to chillerneighboring rural areas," according to Sobrino et al. (2013). Frazer (2005) testified that impermeable surfaces have a deleterious relationship with environment, as they have a more thermal capacity than green areas. Lahoremetropolitan city has experienced substantial growth in terms of its unplanned population growth and geographical administrative area in recent years. Due to the ruralurban migration Lahore city experienced unplanned urban growth .Being the administrative, financial and cultural hub led to consistent urbanization expansion of the city, to lodge the increasing population growth. For modelling climate change and greenhouse (e.g. Global warming) effects LST measurements are flattering popular (Dousset and Gourmelon 2003). Urban areas having paved roads, settlements, houses and other concrete structures have a higher surface temperature owing to impact of land surface temperature (LST), while green areas and vegetative cover having lower surface temperature due to greenness (Kumar et al. 2012). Currently urban Planners and policy makers are using land surface temperature LST information for batter urban planning as it is the leading factor of directing the urban climate.

LST has antagonistic impressions on the atmosphere and physical environment elements. It embroils in the process of escalating heat flux exchanges land radiation in the atmosphere For instance, (Alsultan, 2005). For studying local regional and global environmental change LST is a key factor forguesstimating surface and atmosphere energy exchanges (Lo and Quattrochi 2003; Wan and Dozier 1996; Mallicket al. 2008). Through the Understanding of LST distribution over area urban planners will be able to discover new ways of solving urban problems for the city of Lahore.It is necessary to determine the occurrence and extent of the LST for the city of Lahore during this study. Land use land cover (LULC) relationship with LST can also be observed areas of Lahore that may have gone through perceptible changes over period under observation will be identified.

\section{Land Surface Temperature (LST)}

Land surface temperature (LST) is a significant consideration which is convoluted in evapotranspiration procedure and energy balance, land surface temperature (LST) basically involves 
between the interaction of ground and atmosphere (Alsultan et al. 2005). Valiente et al (2010) meteorological stations usually measured land surface air temperature as the air temperature near the earth's surface. Crust temperature of the land surface means LST .Heat transformation process between surface of earth and atmosphere is dependent on many factors including soil moisture rate, surfaceemission, type of material on the earth's surface and solar radiation (Sun 2003; Rinner and Hussain 2011).

Land Surface Temperature (LST) also affect by several factors like the amount of exposure to sunlight, Earth's energy balance, and cloud, It is an intrinsic feature affecting most, physical biological processes of the Earth and chemical process(Becker and Li. 1990). Spectral radiance needs to be calculated before estimating the LST. Sensor calibration data for the specific satellite is used for transforming the Digital Number (DN) values of the individual pixels of the satellite image into spectral radiance (Markham and Barker 1986). Landsat(TM) TIR images can be used for regional or local scale study of LST (Larson and Carnahan 1997). For larger area remote sensing satellites is chosen over point dimensions on the ground for the LST (Dash et al. 2002).

\section{Study Area}

Lahore district is a district in the Punjab province of Pakistan that contains the city of Lahore, the district and provincial capital. Total area is about $1772 \mathrm{~km}^{2}$. Comprises of ten major administrative towns. Pakistan's most accessible city one can fine transportation and other facilities almost 24 hours. The roads in the city are well maintained and are broadened to meet thecontinuously increasing population.

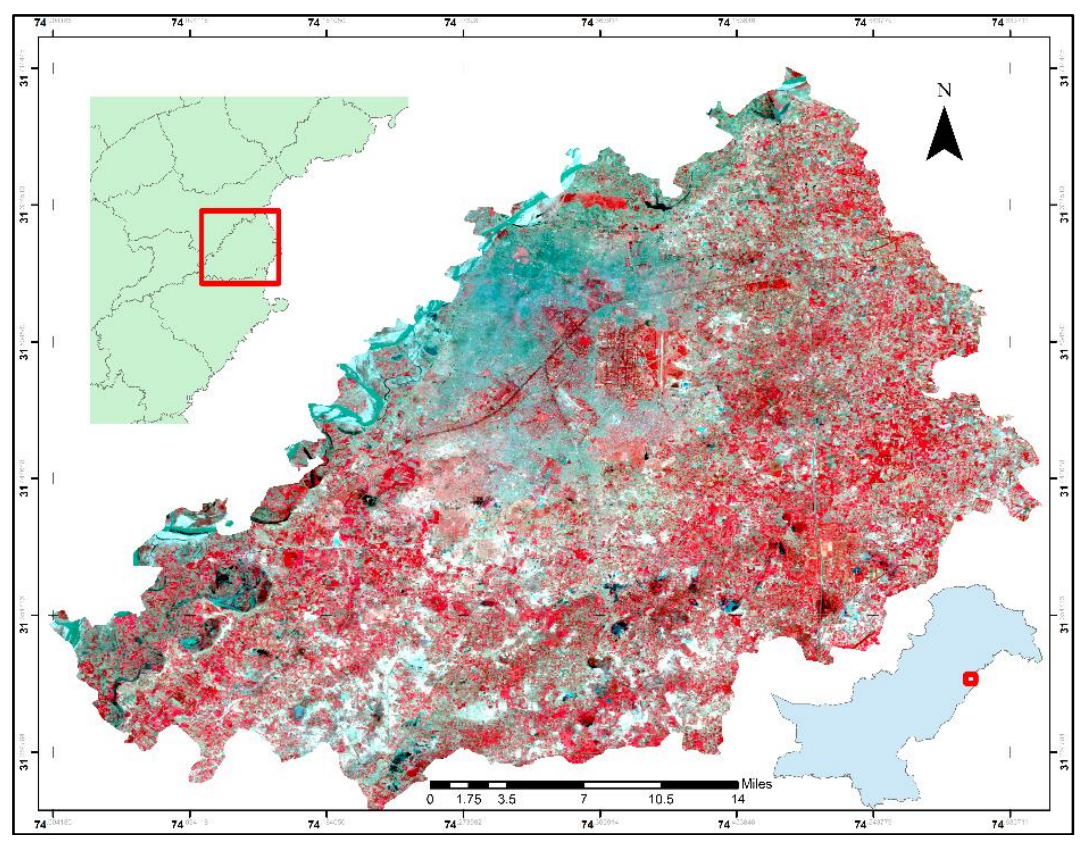

Fig. 1. Study Area District Lahore, Pakistan.

\section{Data and Methodology}

\section{Image pre-processing}

Landsat TM images were obtained from 4 different temporal years 1996,2010,2013,2017 respectively, images used are from the similar season. Images were geo-referenced to a common geographical coordinate system (WGS 84).Images were clipped on study area boundary using Lahore 
District Shapefile. By using radiometric corrections DN were converted to satellite radiance which is further converted to surface reflectance.

\section{Image classification}

For concealment of LULC during the speedy urbanization since the 1996s, land cover classification is required to examine the impressions of human activities on regional scale. In this study, the Landsat Thematic Mapper (TM) data acquired on 1996, 2010, 2013 and 2017 were used. Images were classified into major four classes, the categories include: (1) built-up area, (2) vegetated areas, (3) water bodies and (4) bare land. An unsupervised classification technique were used with Iso-data algorithm employed to classify the Landsat images to quantify each land use class.

\section{LST Calculation}

LST is actually skin temperature of the land surface, which effects through the process of water and energy exchanges through the atmosphere. The LST from satellite thermal data can be derivedfrom different procedures:atmospheric, radiometric calibrations and surface emissivity corrections, classification of spatial changeability in land-cover, etc.

Due to seasonal and inter-annual variability of the atmospheric conditionsatmospheric water vapor content varies over time. This UHI result can be firm for the discrete thermal images and then compared between multiple periods. Landsat TM thermal infrared band $(10.4-12.5 \mu \mathrm{m})$ data were used to derive the LST. LST is derived from two steps: First of all, the digital numbers (DNs) are converted to top-of-atmospheric (TOA) radiance $\left(L_{\lambda}, \mathrm{mW} /\left(\mathrm{cm}^{2} \mathrm{sr} \cdot \mu \mathrm{m}\right)\right.$ using (Eq. 2) (Chander and Markham 2003).

\section{Top of Atmospheric Spectral Radiance (TOA)}

Landsat OLI and TIRS bands data can be converted to Top of Atmospheric Spectral Radiance (TOA) using the radiance rescaling factors provided in the metadata file. According to USGS website following formula is used to calculate TOA.

$$
\mathrm{L}_{\lambda}=\mathrm{M}_{\mathrm{L}} \mathrm{Q}_{\text {cal }}+\mathrm{A}_{\mathrm{L}}
$$

Where

$\mathrm{L}_{\lambda}=$ TOA spectral radiance $($ Watts $/(\mathrm{m} 2 * \operatorname{srad} * \mu \mathrm{m}))$

$\mathrm{M}_{\mathrm{L}}=$ Band-specific multiplicative rescaling factor from the metadata

(RADIANCE_MULT_BAND_x, where $\mathrm{x}$ is the band number)

$A_{L}=$ Band-specific additive rescaling factor from the metadata

(RADIANCE_ADD_BAND_x, where $\mathrm{x}$ is the band number)

$\mathrm{Q}_{\mathrm{cal}}=$ Quantized and calibrated standard product pixel values (DN)

$L_{\lambda}=\frac{\left(L_{\max }-L_{\min }\right)}{\left(Q C A L_{\max }-Q C A L_{\min }\right)} \times\left(D N-Q C A L_{\text {min }}\right)+L_{\text {min }}$

Where DN is the pixel digital number for band 6, max $Q C A L_{\max }=255$ is Maximum quantized calibrated pixel value corresponding to $L_{\max }, Q C A L_{\min }=0$ is Minimum quantized calibrated pixel value corresponding to $L_{\min }, L_{\max }=17.04\left(\mathrm{~mW} / \mathrm{cm}^{2} \mu \mathrm{m}\right)$ is spectral at-sensor radiance that is scaled to $Q C A L_{\text {max }}$ and $\min \mathrm{L}=0\left(\mathrm{~mW} / \mathrm{cm}^{2} \mathrm{sr} \cdot \mu \mathrm{m}\right)$ is spectral at-sensor radiance that is scaled to $Q C A L_{\text {min }}$.

Secondly: to top-of-atmospheric (TOA) radiance $\left(L_{\lambda}, \mathrm{mW} /\left(\mathrm{cm}^{2} \mathrm{sr} \cdot \mu \mathrm{m}\right)\right.$ was converted to surface temperature using the Landsat specific estimate of the Planck curve (Eq. 3) (Chander and Markham 2003). 
Usman Ahmed Khan

$$
\mathrm{BT}=\frac{\mathrm{K}_{2}}{\ln \left(\left(\frac{\mathrm{K}_{1}}{\mathrm{~L}_{\lambda}}\right)+1\right)}-273.15
$$

Where

$B T=$ Top of atmosphere brightness temperature (C)

$\mathrm{L}_{\lambda}=$ TOA spectral radiance (Watts $\left./\left(\mathrm{m}^{2} * \operatorname{srad}^{*} \mu \mathrm{m}\right)\right)$

$\mathrm{K}_{1}=$ Band-specific thermal conversion constant from the metadata

(K1_CONSTANT_BAND_x, where $\mathrm{x}$ is the thermal band number)

$\mathrm{K}_{2}=$ Band-specific thermal conversion constant from the metadata

(K2_CONSTANT_BAND_x, where $\mathrm{x}$ is the thermal band number)

\section{Result and Discussion}

\section{Land use/cover changes}

The LULC images generated using satellite images from 996, 2010, 2013 and 2017 respectively in Fig 2.Images were classified into major four classes, the categories include: (1) built-up area, (2) vegetated areas, (3) water bodies and (4) bare land. An unsupervised classification technique were used with Iso-data algorithm employed to classify the Landsat images to quantify each land use class.

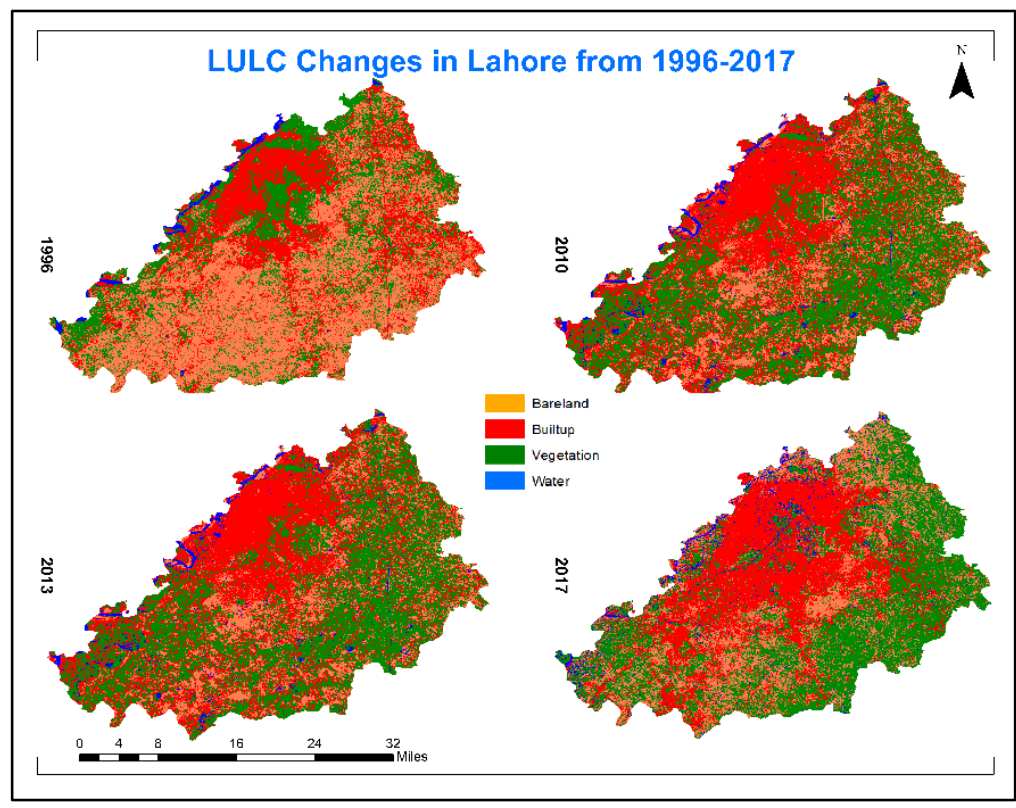

Fig. 2. Classified satellite images of Lahore in Oct, 1996, 2010, 2013 and, 2017.

Urbanization can be seen through satellite images from 1996-2017 in Fig 3, same area can be observed in different four temporal images from 1996 to 2017 continuous growth of urban area in prominent.

Satellite images transition zones are very prominent in images, where we can see an incremental urbanization in Fig 5 and Fig 6respectively. Fig 5 actually area that is nowadays called "New Lahore". Fig 6 showing east and south part of Lahore having considerable urban growth in major geographical area.

Land use/land cover (LULC) of Lahore District for the years 1996 to 2017 was derived from Landsat data through unsupervised image classification and the maps are presented in figure 1. Statistics of Area in ha for the classes in images i.e. water, vegetation, urban areas and bare land and the results of change analysis for the years 1996 to 2017 are potted in Tab. 1. The change analysis outcomes in 
table 1 for the periods of 1996-2010, 2010-2013 and 2013-2017 exhibited that there is a substantial decline in vegetative cover and incremental inclination in bare land and urban area. Depending upon weather condition, water flow and seasonal variation water bodies are quite stable.

In Tab. 1. we can see that there is a declining trend of about 5\% in vegetation class from 19962010. Urbanarea increased by $18 \%$ that is actually considerable increasing trend. This urbanization majorly to the development of new, and expansion of existing housing schemes to accommodate exponentially increasing unplanned population. The period of 2010-2013 and 2013-2017 there is almost constant rate of urbanization and decrease in vegetation. The period of 1996-2017 was again a period of higher variation in the land use, bare lands shrunk by $12 \%$ incrementing the urban areas by $48 \%$ and vegetation shrunk by $19 \%$.The rate of urban sprawl have been alarming with an increase in urban area by $48 \%$ during this period.

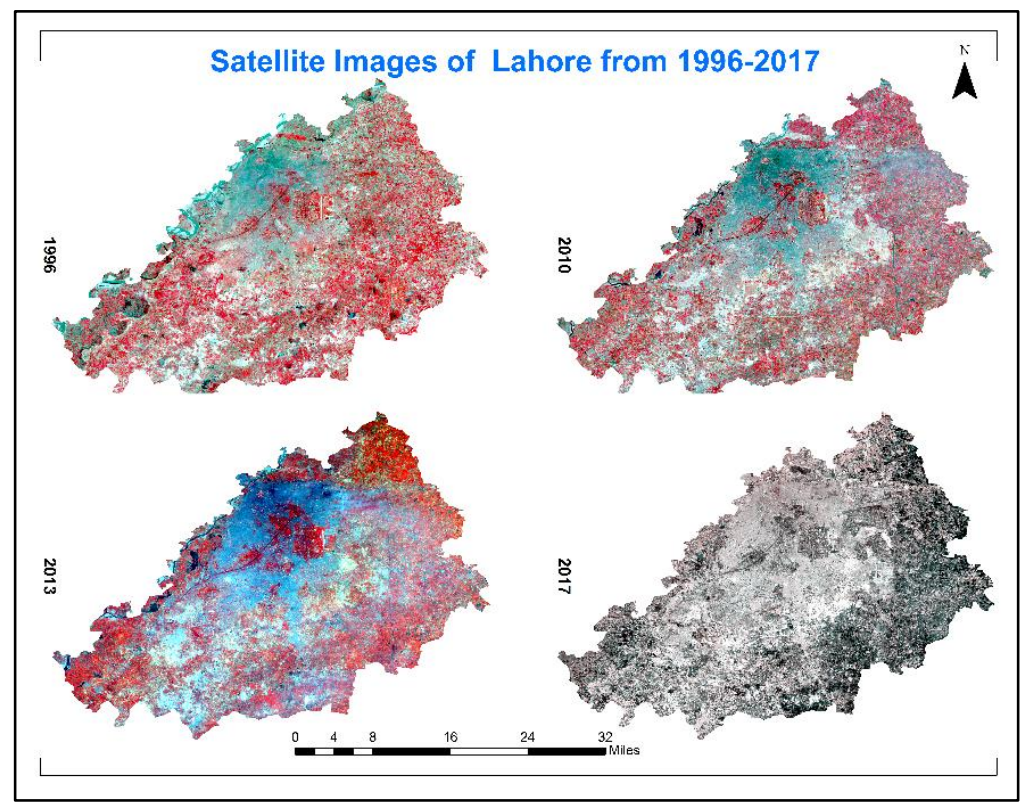

Fig. 3. Satellite images of Lahore in 1996, 2010, 2013 and, 2017.

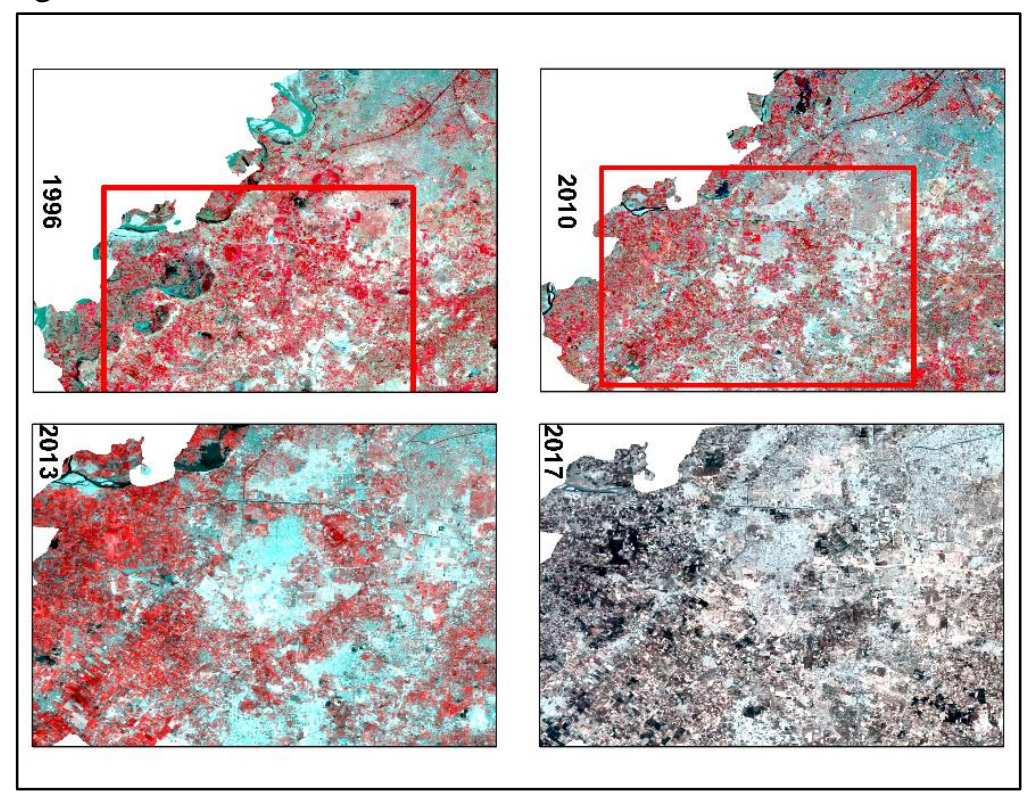

Fig. 4. Urbanization through satellite images of Lahore in 1996, 2010, 2013 and, 2017. 


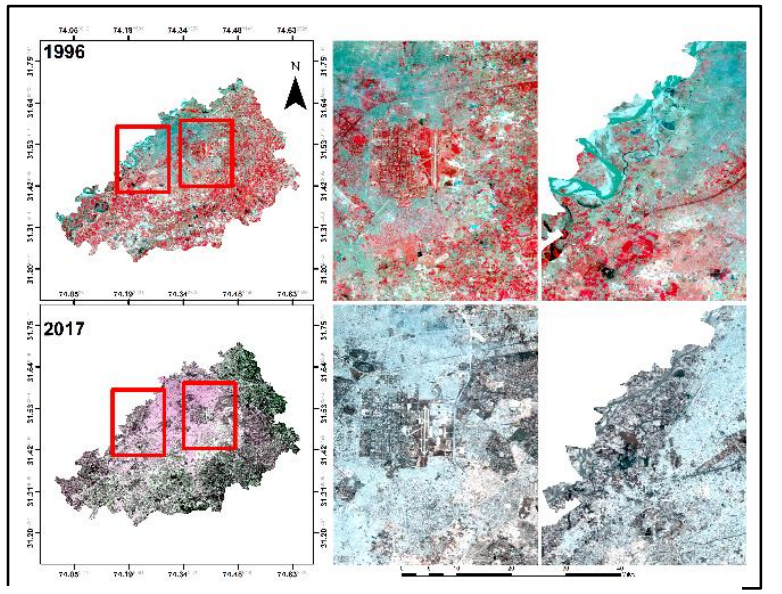

Fig. 5. Urbanization change detection through satellite images from 1996 to 2017

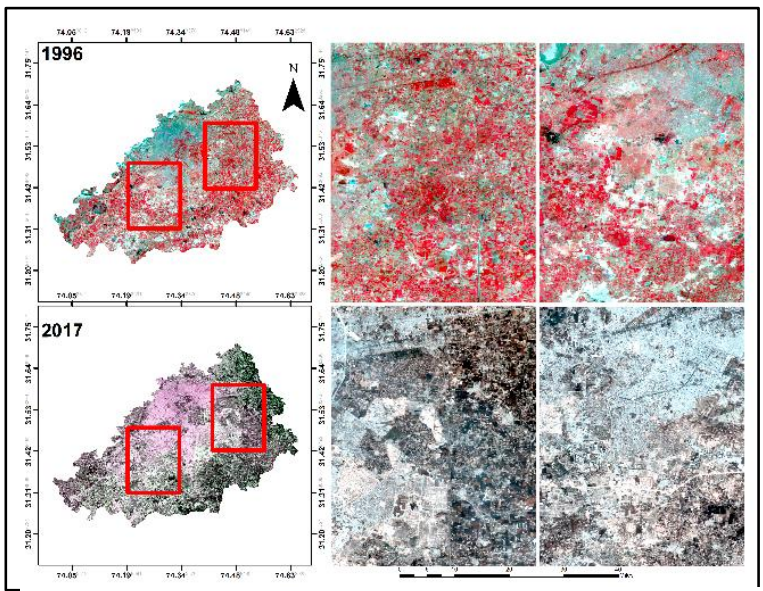

Fig. 6. Urbanization change detection through satellite images from 1996 to 2017.

Tab. 1. Classification matrix of study area from 1996-2017 (ha).

\begin{tabular}{|c|c|c|c|c|c|c|c|c|c|c|c|c|}
\hline \multirow{2}{*}{ Class } & \multicolumn{4}{|c|}{ Area (ha) } & \multicolumn{4}{|c|}{ Change in Area (ha) } & \multicolumn{4}{|c|}{ Change in Area (\%) } \\
\hline & 1996 & 2010 & 2013 & 2017 & $\begin{array}{l}\text { 1996- } \\
2010\end{array}$ & $\begin{array}{l}2010- \\
2013\end{array}$ & $\begin{array}{l}2013- \\
2017\end{array}$ & 1996-2017 & $\begin{array}{l}1996- \\
2010\end{array}$ & $\begin{array}{l}2010- \\
2013\end{array}$ & $\begin{array}{l}2013- \\
2017\end{array}$ & $\begin{array}{l}1996- \\
2017\end{array}$ \\
\hline Water & 2252.78 & 2279.35 & 1749.56 & 2083.45 & 26.6 & -529.8 & 333.9 & -169.3 & $1 \%$ & $-23 \%$ & $19 \%$ & $-8 \%$ \\
\hline Vegetation & 76829.85 & 72717.17 & 67929.65 & 62544.99 & -4112.7 & -4787.5 & -5384.7 & -14284.9 & $-5 \%$ & $-7 \%$ & $-8 \%$ & $-19 \%$ \\
\hline Urban & 43692.81 & 51429.65 & 57495.25 & 64665.55 & 7736.8 & 6065.6 & 7170.3 & 20972.7 & $18 \%$ & $12 \%$ & $12 \%$ & $48 \%$ \\
\hline Bare land & 50988.65 & 47538.68 & 46790.25 & 44670.55 & -3450.0 & -748.4 & -2119.7 & -6318.1 & $-7 \%$ & $-2 \%$ & $-5 \%$ & $-12 \%$ \\
\hline
\end{tabular}

\section{LST results}

The LST images generated using satellite images from 1996, 2010, 2013 and 2017 respectively. LST map generated in Fig 7.Calculations performed over each images to get LST.There is actually a positive LST, in every year there is an increase in LST due to urbanization in city.in 1996 the LST minimum value was $16^{\circ} \mathrm{C}$ and maximum was $21^{\circ} \mathrm{C}$.From $1996-2010$ it increased up to $26^{\circ} \mathrm{C}$ maximum which shows incremental trend in LST, in 2013 the LST minimum value was $21^{\circ} \mathrm{C}$ and maximum was $27^{\circ} \mathrm{C}$ and finally in 2017 the LST minimum value was $26^{\circ} \mathrm{C}$ and maximum was $31^{\circ} \mathrm{C}$.during daytime Lahore city has a positive LST.like Lahore city other major cities showed a positive increased LST at day time due to urbanization and paved structure .Actually paved concrete structures absorb energy at day time and emit at night time.

In Fig. 8 the portent of surface UHI, the average LSTs of urban area were calculated in the Lahore District using satellite images. The mean LST of Lahore District in 1996, 2010, 2013, and 2017 were $18.5{ }^{\circ} \mathrm{C}, 22{ }^{\circ} \mathrm{C}, 24{ }^{\circ} \mathrm{C}$, and $28.5{ }^{\circ} \mathrm{C}$, respectively. The LST maximum and minimum of study area in the same periods are shown in Fig 8 respectively.

\section{Transition Zones}

LULC maps generated through unsupervised classification. There are many geographical locations in Lahore district which have undergone a transition from bare and vegetation land to urban land, ultimately increase in LST.Most of land had been bought up by Lahore Development Authority or by the private housing developers which was previously agriculture or barren land. Authorities and other land mafia cleared agriculture fields and natural vegetative cover and converted into new housing 
societies, housing plots, other infrastructure and road network to accommodate the urban population growth.Transitional Phase is a process of conversion of agriculture land from rural areas into suburban towns.

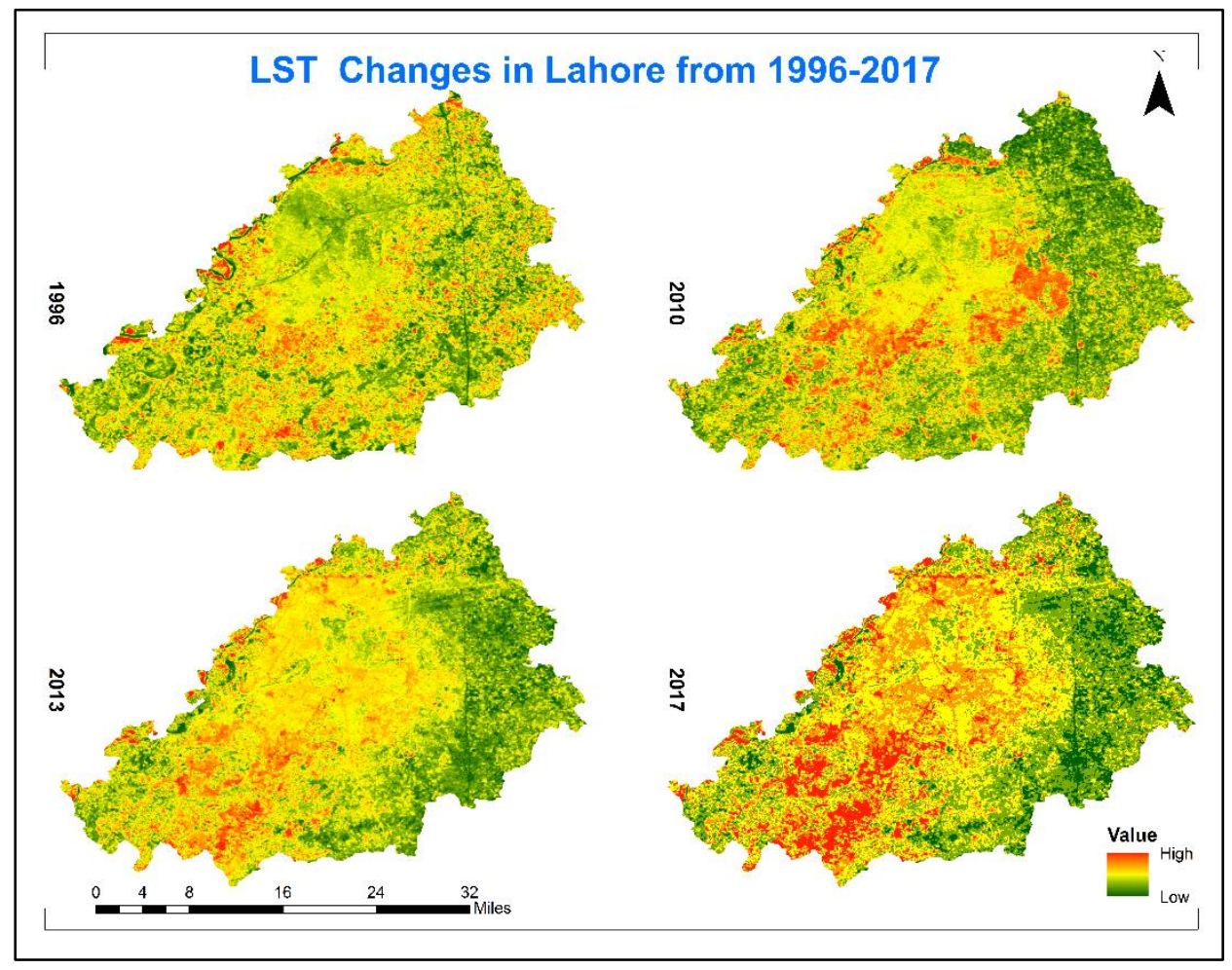

Fig. 7. LST maps of Lahore in Oct, 1996, 2010, 2013 and, 2017.

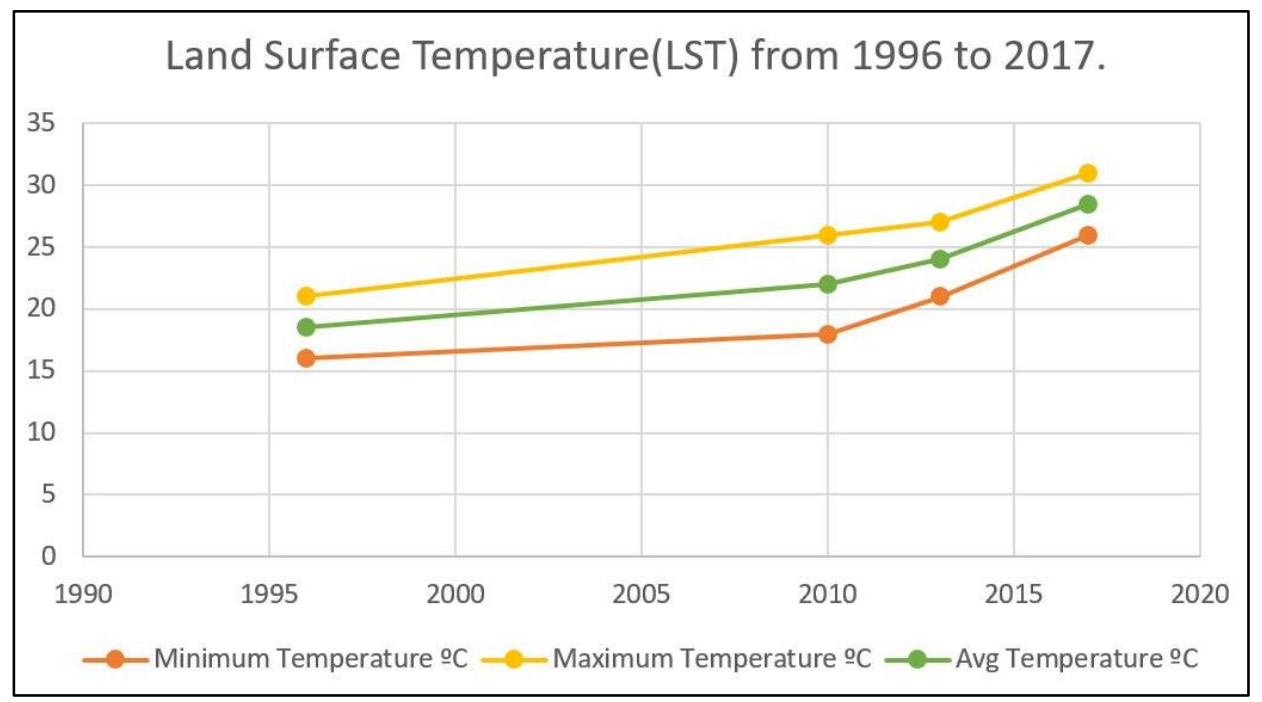

Fig. 8. LST maps of Lahore in Oct, 1996, 2010, 2013 and, 2017.

There are many transition zones having development pattern of new housing societies around Lahore.in Fig 9 there is a major change in temperature from 1996-2017 due to unplanned urbanization.in Fig 8 the average temperature was $18^{\circ} \mathrm{C}$ in 1996 and in 2017 it was actually $29^{\circ} \mathrm{C}$.west part experienced lot of changes due to increase in urbanization. 


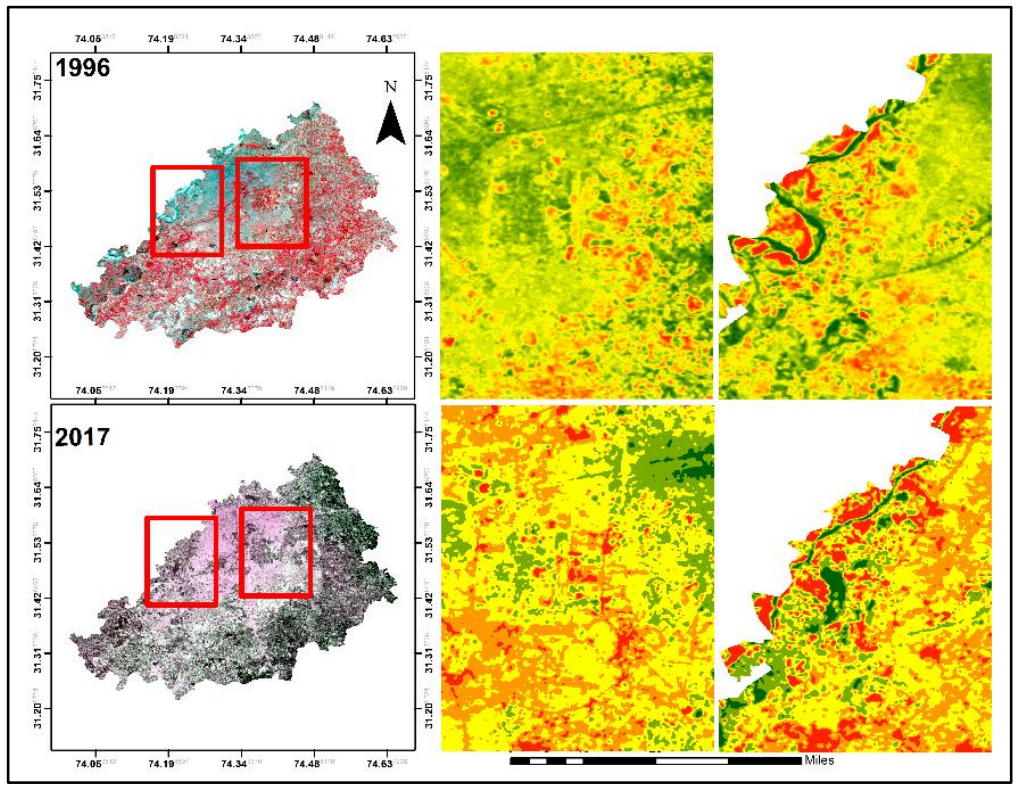

Fig. 9. LSTtransition map of Lahore from 1996-2017.

Same is the case with 2010-2017 major change in temperature from 2010-2017 due to unplanned urbanization and population growth.in Fig 10 the average temperature was $25^{\circ} \mathrm{C}$ in 2010 and in 2017 it was actually $29^{\circ} \mathrm{C}$.west and southern part experienced lot of changes due to increase in urbanization and newly built housing societies.

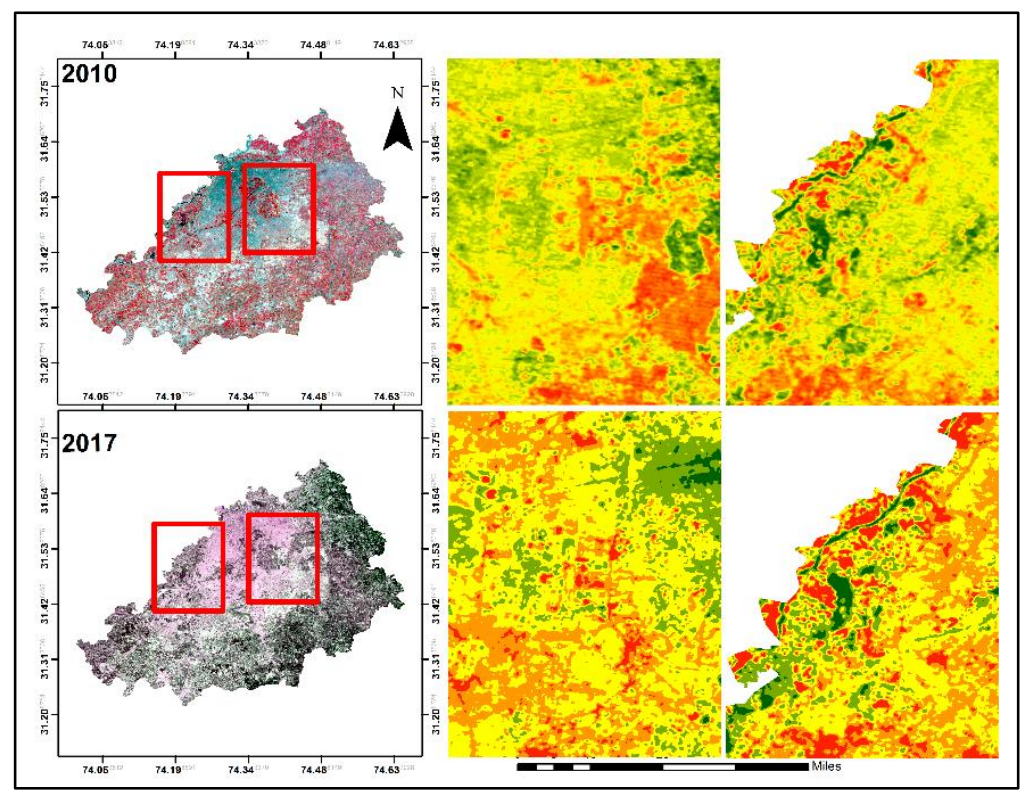

Fig. 10. LST transition map of Lahore from 2010-2017.

Actually the area near to airport gone through transition zone also due to major housing society DHA, having different phases developed and some are under development phase.in Fig. 11 clearly seen LST of Lahore in 1996 and 2017.near airport and southern part Lahore experienced greater increase in LST average increased from $1996-2017$ is about $10^{\circ} \mathrm{C}$.

Majority of pixels in Fig. 10. and Fig. 11. shows a shifting of pixels towards warmer LST classes. These changes can also be better understood by observing the LULC maps of same year the 
vegetative areas converted into bare and urban areas. From 1996-2017 urban areas increased to about considerable increase of about $48 \%$.few areas of city also shown in reduction in LST from year 19962017that actually began their transitional phase from rural to urban LULC.Mean temperature of city increased averagely about $1^{\circ} \mathrm{C}$ each year in the month of October. The green and vegetative areas witnessed a decrease in area while higher number of pixels increased in urban class.

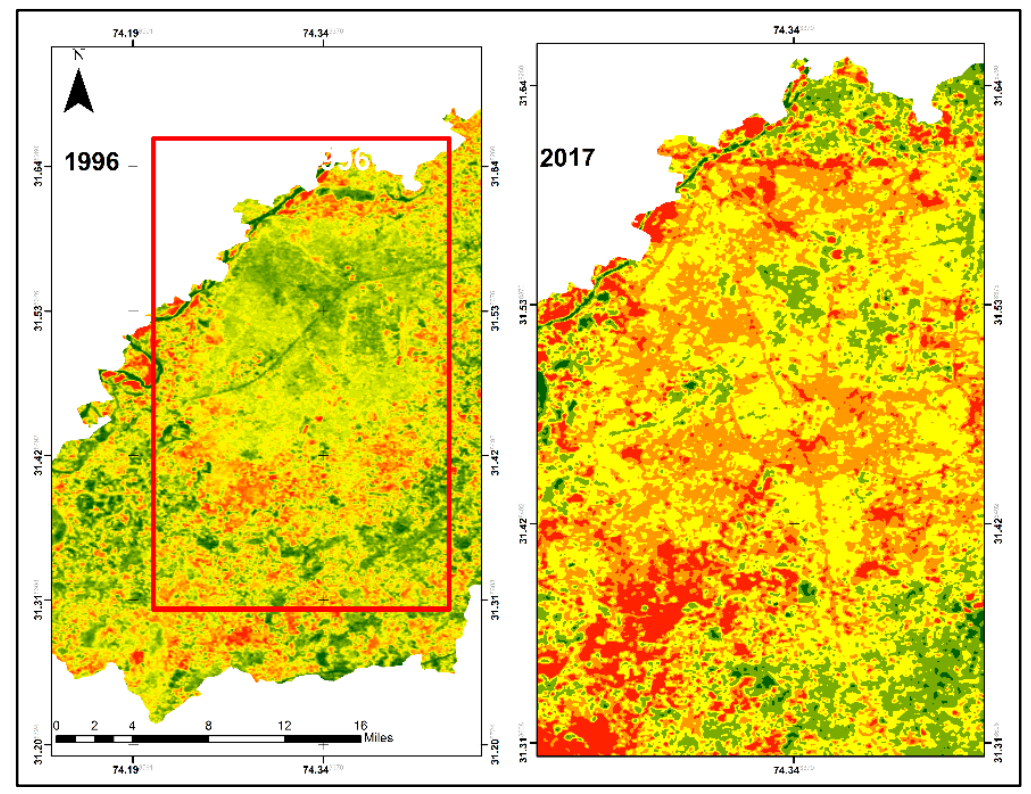

Fig. 10. LST transition map of Lahore from 1996-2017.

\section{Conclusion}

In this study LULC and LST changes examined in Lahore District, Pakistan from 19962017.urban built-up area expanded dramatically and due to rapid population growth. There was an evident of decrease in vegetative cover in 2010,2013 and 2017 respectively from 1996-2017 vegetative cover wilted observed to about $19 \%$ and which is converted into bare land and urban land. Urban land increased to about 48\% from 1996-2017. Changes in LULC were principally accredited due to population growth pressure on the land, meager land use planning, and the irregularity in the governmental policies and rapidly growing economy. Changes in LULC were escorted by changes in LST. Surface temperature climbed from 1996 to 2017 continued to increase, due to urban expansion. Built up and surrounding rural areas temperature differences widened significantly.

Unplanned societies and poor development built-up areas will increase dramatically this rise in high density built up class lead to the rise in average land surface. Lahore city is not growing in a similar patterns as it was back in 1996, it actually growing randomly in every part of Lahore district ultimately it is increasing land surface temperature around whole district. Satellite data substantiated priceless for the calculation of that allows to get data over larger area simultaneously. Through a ground survey it may not be feasible to gather LST measurements in urban areas spanning several hundred square kilometers across the entire area simultaneously. Remote sensing data make available us with the skill of wide-area coverage, and eliminate problems of accessibility.Even if such a survey were conducted it need to be exclaimed to get extensive area analysis. The compromising feature of using satellite data is that it is only allows to measure the LSTs of horizontal surfaces. Remote sensing satellite images offer a distinctive knack of cost effective LST over large area, mapping land cover, at a regional scales and with accuracy. There is the need to focus on: (1) assessment of the impression of the urban growth patterns on urban climate, and (2) relationship between urban planning and green area coverage. 


\section{Recommendations}

The warmest class in LULC is urban/built-up, it would thus be recommended to the development agencies, government organizations, city planners, and policy makers to restrict the unplanned urban growth and to increase the plantation in already built-up areas. Around cities green areas must not convert into barren land or built-up, even expansion is required in any case green areas must be design smartly and urban areas should be planned and execute properly. Researches should incorporate atmospheric data with satellite data to get a deeper insight and to analysesatmospheric effects on urban expansion. Study span should be in decades for batter panning and to understand the transition phases in urban expansion.

\section{References}

Artis DA, Carnahan WH (1982) Survey of emissivity variability in thermography of urban areas. Remote Sens. Environ, 12, 313-329.

Akbari H, Rosenfeld A, Taha H, Gartland L(1996) Mitigation of summer urban heat islands to save electricity and smog. In 76th Annual American Meteorological Society Meeting Atlanta, GA

Akbari H, Pomerantz M, Taha H (2001) Cool surfaces and shade trees to reduce energy use and improve air quality in urban areas. Solar Energy, 70, 295-310.

Becker F, Li ZL (1990) Towards a local split window method over land surfaces," Intern. J. Remote Sens., 11, 369-393.

Barsi JA, Schott JR, Palluconi FD, Helder DL, Hook SJ, Markham BL, Chander G, O’Donnell EM (2003) Landsat TM and ETM+ thermal band calibration. Canadian Journal of Remote Sensing, 29(2), 141-153.

Bretz S, Berdahl P (1997) Preliminary survey of the solar reflectance of cool roofing materials. Energy Build, 25, 149-158.

Chen ZM, Babiker IS, Chen ZX, Komaki K, Mohamed MAA, Kato K (2004) Estimation of interannual variation in productivity of global vegetation using NDVI data. International Journal of Remote Sensing, 25 (16), 3139-3150.

Carnahan WH, Larson RC (1990) An analysis of an urban heat sink. Remote Sens. Environ, 33, 65-71.

Carson TN, Gillies RR, Perry EM (1994) A method to make use of thermal infrared temperature and NDVI measurements to infer surface soil water content and fractional vegetation cover. Remote Sensing Reviews, 9, 161-173.

Dash P, Göttsche FM, Olesen FS, Fischer H (2002) Land surface temperature and emissivity estimation from passive sensor data: theory and practice-current trends. Intern. J. Remote Sens., 23, 2563-2594

EOSAT Landsat Tech. Notes., 3-8.; Oke TR (1982) The energetic basis of urban heat island. J. R. Met. Soc., 108, 1-24.

Gallo KP, McNab AL, Karl TR, Brown JF, Hood JJ, Tarpley JD (1993) The use of a vegetation index for assessment of the urban heat island effect, Intern. J. Remote Sens., 14, 22232230. Gallo, K.P., and T.W. Owen, 2002: A sampling strategy for satellite sensorbased. Intern. J. Remote Sens., 23, 1935-1939.

Gillies RR, Carlson TN (1995) Thermal remote sensing of surface soil water content with partial vegetation cover for incorporation into climate models. Journal of Applied Meteorology, 34, 745756.

Gibbons DE, Wuckelick GE (1989) Application of LANDSAT thematic mapperdata for coastal thermal plume analysis at Diablo Canyon. Photogramm. Eng. Remote Sens., 55, No. 6, 903909.

$\mathrm{Hu}$ Y, Jia G (2010) Influence of land use change on urban heat island derived from multisensor data. Int. J. Climatol., 30, 1382-1395.

Larson RC, Carnahan WH (1997) The influence of surface characteristics on urban radiant temperatures. Geocarto Int., 12, 5-16.

Markham BL, Baker JK (1985) Spectral Characteristics of the LANDSAT Thematic Mapper Sensors. Intern. J. Remote Sens., 6, 697-716. 
Myneni RB, Dong J, Tucker CJ, Kaufmann RK, Kauppi PE, Liski J, Zhou L, Alexeyev V, Hughes MK (2001) A large carbon sink in the woody biomass of Northern forests. Proc. Natl. Acad. Sci. U.S.A., 98, 14784-14789.

Markham BL, JL Barker (1986) Landsat MSS and TM post-calibration dynamic rangers, exoatmospheric reflectance and at satellite temperatures.

Peng S et al. (2012) Surface Urban Heat Island Across 419 Global Big Cities. Environ. Sci. Technol., 46, 696-703.

Sobrino JA, Raissouni N, Li ZL (2001) A comparative study of Land Surface emissivity retrieval from NOAA data. Remote Sens. Environ, 75, 256-266.

Rao PK (1972) Remote sensing of urban "heat islands" from an environmental satellite. Bulletin of the American Meteorological Society, 53, 647-648.

Sobrino JA (2013) Evaluation of the surface urban heat island effect in the city of Madrid by thermal remote sensing. Intern. J. Remote Sens., 34, 3177-3192.

Sobrino JA, Jimenez-Munoz JC, Paolini L (2004) Land Surface Temperature Retrieval from LANDSAT TM 5. Remote Sens. Environ. 90, 434-440.

Stathopoulou M, Synnefa A, Cartalis C, Santamouris M, Karlessi T, Akbari H (2009) A surface heat island study of Athens using high-resolution satellite imagery and measurements of the optical and thermal properties of commonly used building and paving materials. Intern. J. Sustain. Energ, 28, 59-76.

Tiangco M, Lagmay AMF, Argete J (2008) ASTER-based study of the night-time urban heat island effect in Metro Manila. Intern. J. Remote Sens., 29, 2799-2818.

Voogt, JA, Oke TR (2003) Thermal remote sensing of urban areas. Remote Sensing of Environment, $86,370384$.

Weng Q, Lu D, Schubring J (2004) Estimation of land surface temperature-vegetation abundance relationship for urban heat island studies. Remote Sens. Environ, 89, 467-483.

Weng Q, Lo CP (2001) Spatial analysis of urban growth impacts on vegetative greenness with Landsat TM data. Geocarto International, 16 (4), 17-25.

Yuan F, Sawaya KE, Loeffelholz BC, Bauer ME (2005) Land cover mapping and change analysis in the Twin Cities Metropolitan Area with Landsat remote sensing. Remote Sensing of Environment, $98(2.3), 317328$. 